\title{
Research on multi-objective planning and optimization of integrated energy system based on economy and environmental protection
}

\author{
Xiaohui Wang ${ }^{1}$, Lu Xue ${ }^{2, *}$, Yongli Wang ${ }^{2}$, Yuli Zhang ${ }^{2}$, Yijiang Liu ${ }^{1}$ \\ ${ }^{1}$ State Grid Economic and Technological Research Institute Co., Ltd., Changping District, Beijing 102209, China \\ ${ }^{2}$ North China Electric Power University, Beijing, 102206, China
}

\begin{abstract}
The development of a regional integrated energy system is an important way to improve energy utilization, alleviate the problem of renewable energy consumption and improve the environment. Aiming at the problems of single planning technology and fewer resource types in the existing integrated energy system planning, various types of equipment in the integrated energy system were built, and the integrated energy system was established with the goal of optimal economy and certain environmental protection. The system multi-objective planning optimization model, and then the particle swarm algorithm is used to solve the example problem to verify the feasibility and economy of the model and the optimization algorithm.
\end{abstract}

\section{Introduction}

As the physical carrier of the energy Internet on the demand side [1], the integrated energy system has also attracted extensive attention and research from scholars at home and abroad. The concept of an integrated energy system originated from research in the field of cooptimization of thermal power. Scholars at home and abroad generally believe that an integrated energy system is organic through the generation, transmission and distribution (energy supply network), conversion, storage, and consumption of various energy sources. After coordination and optimization, a comprehensive social integrated energy production, supply and consumption system is formed [2]. With the gradual refinement of the integrated energy system research, according to geographical factors and the characteristics of energy generation, transmission, distribution and use, the integrated energy system can be divided into inter-regional level, regional level and user level [3]. The cross-regional integrated energy system uses large-scale power transmission, gas and other systems as the backbone grid, with flexible DC transmission, cyber-physical systems and other technologies as the core [4], and mainly plays the role of long-distance energy transmission. The regional integrated energy system is composed of intelligent power distribution systems, medium and lowvoltage natural gas systems, heating/cooling/water systems and other energy supply networks coupled and interconnected, with active power distribution networks, energy conversion and other technologies as the core [5], serving as energy The pivotal role of transmission, distribution, conversion and balance. The user-level integrated energy system is coupled with networks such as smart power systems, distributed/centralized heating systems, and water supply systems, with technologies such as demand response and load forecasting as the core, and there is a deep coupling between energy networks.

Integrated energy system planning technology is the key to achieving system structure optimization and reasonable capacity allocation, and it is also the basis for achieving efficient operation of integrated energy systems. Aiming at the electric-heat coupling planning, literature established a multi-regional CCHP system capacity coordination optimization configuration model with the goal of the economy; literature [6] constructed a combined heat and power (CHP) system and heat pump (HP) integrated system, Multi-objective optimization model, through genetic algorithm to obtain the optimal capacity of each unit. Aiming at electricity-gas coupling planning, Professor Jia Hongjie and other scholars constructed a comprehensive energy system planning model based on energy hubs and performed steady-state solutions [7]; literature [8] established the analysis of energy conversion and interactive power flow of natural gas and power systems model. For electricity-heat-gas coupled planning, literature [9] proposed an IES extended planning method that takes into account the uncertainty of wind power for large-scale wind energy grid connection; literature [10] studied the coupling of electricity-heat-gas The optimization problem of equipment capacity matching in the distributed multi-energy flow integrated energy system.

This article intends to explore in-depth the planning and optimization methods of the integrated energy system, by absorbing more types of energy and multi-form energy conversion methods, to make the integrated energy system configuration more complete, more comprehensive and reasonable. 


\section{Typical structure and equipment of integrated energy system}

\subsection{Typical structure of integrated energy system}

A typical integrated energy system consists of the power system, natural gas system, thermal system, and coupling links. The power system includes power supplies, transformers, transmission and distribution lines, power loads, etc.; the natural gas system includes gas sources, gas transmission and distribution pipe networks, and natural gas loads; thermal systems include heat sources, heating pipe networks, and heat loads; thermal systems include heat sources, Heating pipe network, heat load, etc.; coupling links include various energy conversion, storage equipment, etc. The structure of a typical integrated energy system is shown in Figure 1.

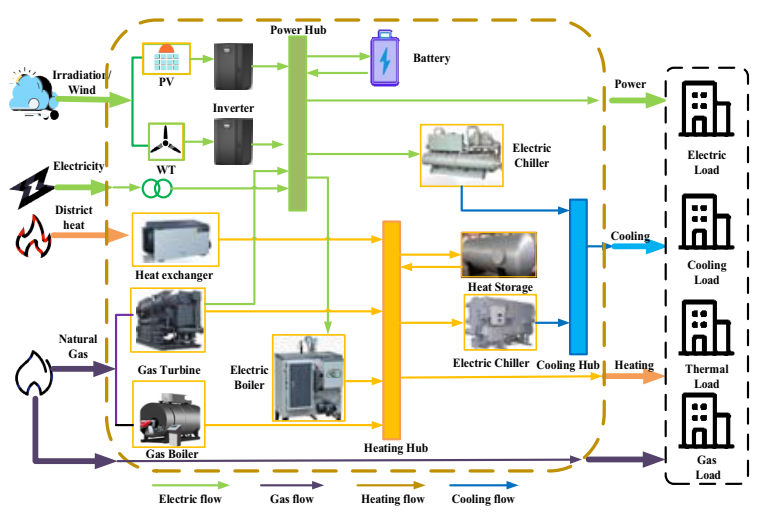

Fig. 1 The structure of typical integrated energy system

\subsection{Typical equipment of integrated energy system}

In the integrated energy system, energy equipment includes independent equipment and coupling equipment.

1. Independent equipment

(1)Wind turbine

$$
P_{W T}=\left\{\begin{array}{c}
0, v \leq v_{c i} \geq v_{c o} \\
P_{r} \frac{v-v_{c i}}{v_{c o}-v_{c i}}, v_{c i}<v<v_{r} \\
P_{r}, v_{r}<v<v_{c o}
\end{array}\right.
$$

Where: $v_{c i}$ is the cut-in wind speed; $v_{c o}$ is the cutout wind speed; $v_{r}$ is the rated wind speed of the fan. When the wind speed is between the rated wind speed and the cut-in wind speed, the function relationship of the output power of the wind turbine is shown in equation (1); $P_{r}$ is the rated power of the wind turbine.

(2) Photovoltaic

$$
P_{p v}=f_{p v} P_{r, p v} \frac{A}{A_{s}}\left[1+\partial_{p}\left(T_{p v}-T_{r}\right)\right]
$$

Where: $f_{p v}$ is the energy conversion efficiency of photovoltaic power output, usually $0.9 ; P_{r, p v}$ is the actual radiation intensity; $\mathrm{A}$ is the rated light intensity;
$A_{s}$ is the temperature power coefficient, usually $0.0047^{\circ} \mathrm{C}-1 ; \quad T_{p v}$ is the actual temperature of the photovoltaic module; $T_{r}$ is the photovoltaic module Rated temperature.

2. Coupling device

(1)Gas boiler

The gas boiler is a gas-heat coupling device, and its model is:

$$
\begin{aligned}
& P_{\text {heat }, G B}(t)=P_{\text {gas }, G B}(t) \eta_{G B} \\
& P_{\text {gas }, G B}(t)=\frac{Q_{G B}(t) \times L_{\Lambda}}{\Delta t} \\
& H_{G B}(t)=P_{\text {heat }, G B}(t) \Delta t
\end{aligned}
$$

Where: $P_{\text {heat }, G B}(t), P_{\text {gas, } G B}(t)$ and $\eta_{G B}$ respectively is the thermal power generated by the gas boiler, the power consumption of natural gas, and the actual conversion efficiency of the gas boiler at time $\mathrm{t} ; Q_{G B}(t)$ and $L_{\Lambda}$ respectively is the intake air volume of the gas boiler and the low heating value coefficient of natural gas at time $t$; $H_{G B}(t)$ is the actual heat value produced by the gas boiler after the $\Delta \mathrm{t}$ period.

(2)Gas turbine

The gas turbine is an electric-thermal coupling device, and its model is:

$$
P_{E G T}(t)=\frac{V_{E G T}(t) L_{N G} \eta_{E G T}}{\Delta t}
$$

Where: $P_{E G T}(t)$ is the electrical output power of the gas turbine during t period; $V_{E G T}(t)$ is the natural gas consumption of the gas turbine during t period; $L_{N G}$ is the low calorific value of natural gas; $\eta_{E G T}$ is the power generation efficiency of the gas turbine; $\Delta t$ is the time step.

(3)Lithium bromide absorption chiller

Lithium bromide refrigerator is a cold-heat coupled device, and its model is:

$$
\begin{gathered}
Q_{c w}=\frac{P_{r e t}\left(1-\eta_{\text {net }}-\eta_{1}\right)}{\eta_{\text {net }}}(1-x(t)) \cdot \eta_{\text {reach }} \cdot C O E_{c o} \\
\eta_{\text {reach }}=\frac{T_{c 1}-T_{c 2}}{T_{c 1}-T_{w}}
\end{gathered}
$$

Where: $Q_{c w}$ is the refrigeration capacity of the absorption chiller in the $\mathrm{t}$ period; $\eta_{\text {recco }}$ is the flue gas waste heat recovery coefficient; $C O E_{c o}$ is the refrigeration coefficient; $T_{c 1}, T_{c 2}$ respectively is the inlet and outlet temperature of the absorption chiller flue gas.

(4) Electric refrigeration

Electric refrigeration is a kind of electric-cold coupling equipment, its model is:

$$
Q_{E C}=C O P_{E C} P_{E C}^{E}
$$

Where: $Q_{\mathrm{C}}$ is the cold output power of the electric refrigerator; $C O P_{E C}$ is the refrigeration coefficient; $P_{E C}^{E}$ is the electric power consumed by the electric refrigerator. 


\section{Model study}

\subsection{Objective function}

(1) Minimum of life cycle cost

The total cost of the whole life cycle mainly includes the initial construction cost of the integrated energy system, the operating cost of the integrated energy system during the life cycle (including energy consumption and labor costs) and the internal maintenance cost of the integrated system. At the same time, consider the government's subsidies for the power generation of the integrated energy system. The objective function is:

$$
\left\{\begin{array}{c}
F=\min \left(C_{i n}+C_{o p}+C_{m c}-C_{b t}\right)= \\
\min \left(f_{i n}(x)+f_{o p}(p)+f_{m c}(p)-f_{b t}(p)\right) \\
C_{i n}=f_{i n}(x) \\
C_{o p}=f_{o p}(p) \\
C_{m c}=f_{m c}(p) \\
C_{b t}=f_{b t}(p)
\end{array}\right.
$$

Where, $f_{\text {in }}(x)$ is the system investment and construction cost, $\mathrm{x}$ is the decision variable for planning and construction (the number of each equipment), which is obtained by the internal method in Section 2; $f_{o p}(p)$ is the system operating cost during the life cycle, that is, the system purchases natural gas, The cost of purchasing electricity from the grid; $f_{m c}(p)$ is the maintenance cost of the system; $p$ is the decision variable of the system operation (the output of each device).

1) Construction cost

The initial construction cost of the integrated energy system is mainly composed of equipment purchase cost, installation cost, land cost and other expenses:

$$
\begin{aligned}
& f_{\text {in }}(x)=\frac{r(1+r)^{y}}{(1+r)^{y}-1}\left(\sum_{i=1}^{n} c^{i} x^{i}+\right. \\
& \left.\sum_{i=1}^{n} j^{i} x^{i}+\sum_{i=1}^{n} t^{i} x^{i}+e l\right)
\end{aligned}
$$

Where, $\mathrm{y}$ is the design life of the system and $\mathrm{r}$ is the discount rate; $c^{i}$ is the purchase cost of each equipment in the integrated energy system; $x^{i}$ is the optimal number of equipment planned; $j^{i}$ is the use of land occupied by each equipment in the integrated energy system Cost; $t^{i}$ is the installation cost of each piece of equipment; $e l$ is the remaining cost spent in the construction phase.

2) Operating costs

The system operating costs that need to be considered in the planning stage of the integrated energy system mainly include: fuel consumption costs during the entire life cycle and electricity purchase costs. The formula is as follows:

$$
f_{o p}(p)=\sum_{i=1}^{n} P^{i} \eta^{i}+\sum_{i=1}^{n} G^{i} \kappa^{i}
$$

Where, $P^{i}$ is the operating output of the $i$-th equipment; $\eta^{i}$ is the power consumption proportional coefficient of the $i$-th equipment; $G^{i}$ is the power output of the $i$-th equipment consuming natural gas, and $\kappa^{i}$ is the gas consumption proportional coefficient of the $i$-th equipment.

3) Maintenance cost

$$
f_{m c}(p)=\sum_{i=1}^{n} x^{i} w^{i}
$$

Where, $f_{m c}(p)$ is the maintenance cost of all equipment throughout the life cycle of the integrated energy system, and $w^{i}$ is the maintenance cost of a single equipment.

(2) Lowest total carbon emissions during the whole life cycle

The objective function for the lowest carbon emissions is as follows:

$$
F=y \sum_{i=1}^{n} x^{i} N^{i}
$$

In the formula: $y$ is the entire system life cycle, and $N^{i}$ is the carbon emissions of the equipment in the unit cycle.

\subsection{Restrictions}

(1) Investment capacity constraints

$$
T_{\max } \geq f_{\text {in }}(x)
$$

Where, $T_{\max }$ is the largest investment capacity for the construction of an integrated energy system.

(2) Operational constraints of energy supply equipment

$$
\left\{\begin{array}{l}
\mathrm{Q}^{i}{ }_{\text {min }} \leq Q \leq Q_{\max }{ }^{i} \\
-\Delta \mathrm{Q}^{i}{ }_{\text {down }} \leq Q_{t}{ }^{i}-Q_{t-1}{ }^{i} \leq \Delta Q_{u p}{ }^{i}
\end{array}\right.
$$

Where, $\mathrm{Q}^{i}{ }_{\text {min }}$ and $Q_{\max }{ }^{i}$ are the minimum power and maximum power for cooling/heating of the $i_{\text {-type }}$ equipment, respectively; $\mathrm{Q}^{i}{ }_{\text {down }}$ and $\Delta Q_{u p}{ }^{i}$ are the ramp rates of the $i_{\text {-type equipment for reducing output }}$ and increasing output, respectively.

(3) Natural gas network capacity constraints

The transmission network constraints include the corresponding physical laws between air pressure and current. The formula is as follows: 


$$
\left\{\begin{array}{l}
c l_{l . y} P Q_{\min , J} \leq P Q_{l, t, u, y} \leq c l_{l . y} P Q_{\max , l} \\
\forall t, \forall u, \forall y, \forall l \in \Omega^{l+} \\
V_{\min , s} \leq V_{s, t, u, y} \leq V_{\max , s} \\
\forall t, \forall u, \forall y, \forall s \in \Omega^{y}
\end{array}\right.
$$

Where, $P Q_{\min , J}$ and $P Q_{\max , l}$ respectively represent the upper and lower limits of natural gas pipeline flow $l, c l_{l . y}$ is the safety fluctuation coefficient of pipeline transmission flow; $V_{\min , s}$ and $V_{\max , s}$ respectively represent the upper and lower limits of gas supply given by weather supplier $S$.

\subsection{Algorithm}

Particle swarm algorithm is a new type of parallel metaheuristic algorithm proposed by Kennedy and Eberhardt in 1995. The algorithm is to simulate the mutual cooperation mechanism in the foraging behavior of birds, fish and other creatures in nature to find the optimal solution to the problem. The basic idea is to start with a random solution and find the optimal solution through iterative calculation. The choice of each particle is determined by the fitness function. The optimal solution sought is used to evaluate the quality of the solution through fitness, and by following the current optimal value to find the global optimal solution. The particle swarm algorithm has simple structure, less professional knowledge involved, easy operation, high precision and fast convergence, so it has received extensive attention from researchers at home and abroad. The basic process of applying particle swarm optimization is as follows:

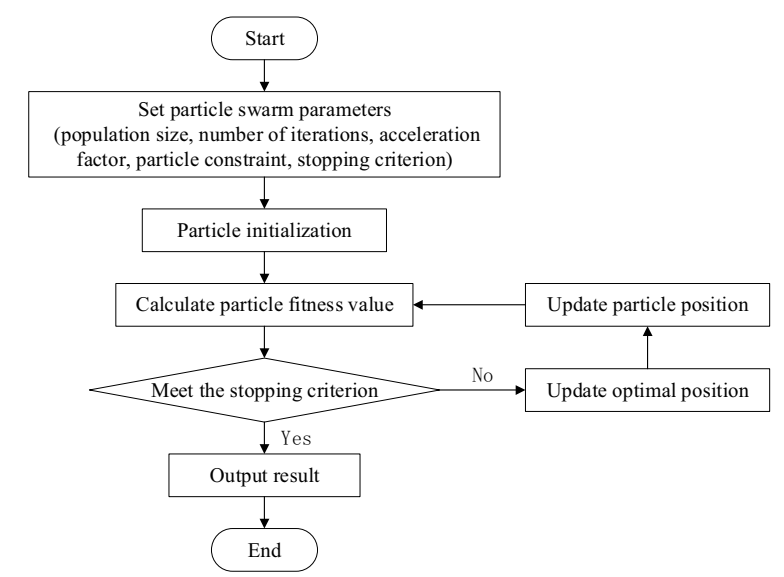

Fig. 2 The basic process of particle swarm optimization

\section{Case validation}

\subsection{Basic data}

This paper selects a certain place in northern China as an example study to verify the validity of the model. Xiong' an New Area is located in the mid-latitude zone, with a warm temperate monsoon continental climate with distinct four seasons, dry and windy in spring, hot and rainy in summer, cool in autumn, and less snow in winter. The annual average temperature is $11.7^{\circ} \mathrm{C}$, the highest monthly (July) average temperature is $26.1^{\circ} \mathrm{C}$, the extreme highest temperature is $40.9^{\circ} \mathrm{C}$ (June 10,1972 ), the lowest monthly (January) average temperature is $-4.9^{\circ} \mathrm{C}$, and the extreme lowest temperature is $-21.5^{\circ} \mathrm{C}$ ( January 5,1970 ); the annual sunshine is 2685 hours, the annual average rainfall is $551.5 \mathrm{~mm}$, the maximum annual extreme precipitation is $1237.2 \mathrm{~mm}$ (1954), and the annual extreme

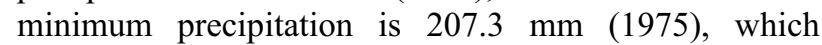
accounts for $80 \%$ June to September. The frost-free period is about 185 days, the longest is 205 days, and the shortest is 180 days. The first frost day occurs on average on October 19, and the final frost day occurs on April 12; the most northerly winds throughout the year, with an average annual wind speed of 2.1 meters $/ \mathrm{Sec}$; the historical extreme maximum wind speed is $20 \mathrm{~m} / \mathrm{sec}$ (March 1972).

The specific planning requirements are as follows:

(1) Equipment type selection

Taking into account the types of loads and resources in the park and the substitutability of various energy sources, this calculation is to choose eight types of equipment including fans, photovoltaics, gas turbines, gas boilers, lithium bromide refrigerators, electric refrigeration, electricity storage, and heat storage. There are three ways for energy transmission: power grid, heating network and cooling network.

(2) Equipment restrictions

Based on the analysis of resources and terrain in the park, it is proposed to set the upper limit of installed wind turbine capacity to $100 \mathrm{MW}$ and the upper limit of installed photovoltaic capacity to $130 \mathrm{MW}$. Due to the lack of data on alternative equipment, this calculation is measured in megawatts, and the ratio of charging and discharging power and capacity of electrical storage equipment is set to $1: 3$, and the ratio of heat storage and release power to capacity of thermal storage equipment is $1: 5$. And set the range of available energy storage capacity to $10 \%-90 \%$.

(3) Energy interaction

Since all four energy supply stations in the park can interact with the power grid, this calculation adopts the grid-connected mode of electric energy, and sets that the four energy supply stations are independent of each other and there is no energy interaction.

\subsection{Output result}

According to the constructed model, the particle swarm algorithm is used to solve the problem using matlab software, and the output result is:

(1) Output results on the supply side

After calculation, the planned installed capacity of each device is as follows:

Table 1 Capacity of each device

\begin{tabular}{|c|c|c|c|c|}
\hline Equipment & $\begin{array}{c}\text { WT } \\
\text { (MW) }\end{array}$ & $\begin{array}{c}\text { PV } \\
\text { (MW) }\end{array}$ & $\begin{array}{c}\text { ESO } \\
\text { (1MW+3 } \\
\text { MWH) }\end{array}$ & $\begin{array}{c}\text { GT } \\
\text { (MW) }\end{array}$ \\
\hline Capacity & 18 & 46 & 29 & 60 \\
\hline
\end{tabular}




\begin{tabular}{|c|c|c|c|c|}
\hline Equipment & $\begin{array}{c}\text { HSO } \\
\mathbf{( 1 M W + 5} \\
\text { MWH) }\end{array}$ & $\begin{array}{c}\text { LB } \\
\text { (MW) }\end{array}$ & $\begin{array}{c}\text { GB } \\
\text { (MW) }\end{array}$ & $\begin{array}{c}\text { ER } \\
\text { (MW) }\end{array}$ \\
\hline Capacity & 15 & 29 & 63 & 84 \\
\hline
\end{tabular}

(2) Analysis of economic output results

As a result of the configuration of this scheme, the average annual total cost is relatively low, and the independence of the distribution network will also be higher, reducing the park's dependence on the large power grid.

Table 2 Average annual total cost

\begin{tabular}{|c|c|}
\hline & Num \\
\hline $\begin{array}{c}\text { Initial investment (ten thousand yuan) } \\
\text { Annual investment (ten thousand yuan) }\end{array}$ & 170451 \\
\hline $\begin{array}{c}\text { Operation and maintenance fee (ten thousand } \\
\text { yuan) }\end{array}$ & 77 \\
\hline $\begin{array}{c}\text { Purchase and sale of electricity (ten thousand } \\
\text { yuan) }\end{array}$ & 2434 \\
\hline Fuel cost of gas boiler (ten thousand yuan) & 1194 \\
\hline Gas turbine fuel cost (ten thousand yuan) & 9136 \\
\hline Power purchase cost (ten thousand yuan) & 3119 \\
\hline Electricity sales income (ten thousand yuan) & 685 \\
\hline Power purchase (10,000 degrees) & 4298 \\
\hline Electricity sales (10,000 degrees) & 990 \\
\hline Total annual cost (ten thousand yuan) & 26518 \\
\hline
\end{tabular}

(3) Analysis of environmental protection output results

The carbon emissions of the integrated energy system mainly come from the carbon emissions of CCHP systems, gas boilers, electric refrigerators and power grids.

Table 3 The output results

\begin{tabular}{|c|c|}
\hline & Num \\
\hline Direct supply plan (10,000 tons) & 237.827 \\
\hline Calculation plan (10,000 tons) & 156.629 \\
\hline Emission reduction (10,000 tons) & 81.198 \\
\hline
\end{tabular}

\section{Conclusions}

This paper proposes a multi-objective integrated energy system planning method, constructs the output model of independent equipment and coupled equipment, adopts multi-objective planning, and plans with the lowest total cost and total carbon emissions during the whole life cycle. The calculation example verifies the validity of the model and algorithm proposed in this paper, which can effectively reduce the total operating cost and carbon emissions of the system, and improve energy efficiency. This paper still has some shortcomings, which will be further improved in the later research.

\section{Acknowledgment}

The authors would like to thank the support of the project "Science and Technology Foundation of State Grid Corporation of China (SGHEJY00JJJS1900017)".

\section{References}

1. Antony A P, Shaw D T. Empowering the electric grid: Can SMES coupled to wind turbines improve grid stability [J]. Renewable Energy, 2016, 89:224-230.

2. JIAHongjie, WANGDan,XUXiandong, YUXiaodan, R esearch on Some Key Problems Related to Integrated Energy Systems [J], Automation of Electric Power Systems , 2015, 39(07):198-207.

3. HUANG Wujing, ZHANG Ning, DONG Ruibiao, LIU Yongxiao, KANG Chongqing, Coordinated Planning of Multiple Energy Networks and Energy Hubs[J] , Automation of Electric Power Systems, 2018, 38(18):5425-5437.

4. WANG Weiliang, WANG Dan, JIA Hongjie, CHEN Zhaoyu, GUO Bingqing, ZHOU Haiming, FAN Menghua, Steady State Analysis of Electricity-Gas Regional Integrated Energy System With Consideration of NGS Network Status[J], Automation of Electric Power Systems. 2018, 38(18):5425-5437.

5. WANG Jun, GU Wei, LU Shuai, ZHANG Chenglong, WANG Zhihe, TANG Yiyuan , Coordinated Planning of Multi-district Integrated Energy System Combining Heating Network Model[J], Automation of Electric Power Systems . 2017, 37(05):1293-1305.

6. Wang X, Yang C, Huang M, et al. Multi-objective optimization of a gas turbine-based CCHP combined with solar and compressed air energy storage system [J]. Energy Conversion and Management, 2018, 164:93-101.

7. $\mathrm{Xu} \mathrm{X,} \mathrm{Jia} \mathrm{H,} \mathrm{Chiang} \mathrm{H} \mathrm{D,} \mathrm{et} \mathrm{al.} \mathrm{Dynamic} \mathrm{Modeling}$ and Interaction of Hybrid Natural Gas and Electricity Supply System in Microgrid[J]. IEEE Transactions on Power Systems, 2015, 30(3):1212-1221.

8. CHEN Linghui. Research on load balancing and decentralized dispatching method of renewable energy power system [J]. Power System and Clean Energy, 2019, 35 (12) : 60-66.

9. HU Wei, HU Yawei, YANG Feng.A wind power prediction neural network model based on improved flower pollination algorithm [J]. Journal of Systems Management, 2019, 28 (5) : 934-940.

10. TAO Zhiyong, CUI Xinxin. A hybrid improved flower pollination algorithm[J]. Transducer and Microsystems, 2019, 38 (10) :139-142, 145. 